OPEN ACCESS

Edited by:

Sara Bonesso,

Ca' Foscari University of Venice, Italy

Reviewed by:

In-Jo Park,

Henan University, China

Heajung Jung,

Konkuk University, South Korea

*Correspondence:

Wenxia Zhou

zhouwx@ruc.edu.cn

Specialty section:

This article was submitted to

Organizational Psychology, a section of the journal

Frontiers in Psychology

Received: 23 November 2019

Accepted: 06 March 2020

Published: 16 April 2020

Citation:

Xin L, Zhou W, Li M and Tang F (2020) Career Success Criteria Clarity as a Predictor of Employment

Outcomes. Front. Psychol. 11:540. doi: 10.3389/fpsyg.2020.00540

\section{Career Success Criteria Clarity as a Predictor of Employment Outcomes}

\author{
Lu Xin ${ }^{1}$, Wenxia Zhou ${ }^{2 *}$, Mengyi Li' ${ }^{2}$ and Fangcheng Tang ${ }^{1}$ \\ ${ }^{1}$ College of Economics and Management, Beijing University of Chemical Technology, Beijing, China, ${ }^{2}$ School of Labor \\ and Human Resources, Renmin University of China, Beijing, China
}

Drawing on the goal-setting theory and social cognitive career theory (SCCT), this study empirically proposes an operational definition of career success criteria clarity (CSCC) and further explores its impact on career satisfaction, person-job fit, and subjective wellbeing through the mediating role of career decision-making self-efficacy (CDSE). A pilot study of 231 samples showed that the CSCC scale had good reliability and validity. To further test the effects of CSCC on crucial employment outcomes, as well as the mediating role of CDSE, 240 employees were included in an additional survey. Structural equation modeling path analysis supported all the expected hypotheses. Results indicated that: (1) CSCC was positively correlated to career satisfaction; (2) CSCC was positively correlated to person-job fit; (3) CSCC was positively correlated to subjective well-being; (4) CSCC was positively correlated to CDSE; (5) CDSE fully mediated the relationship between CSCC and career satisfaction; (6) CDSE fully mediated the relationship between CSCC and person-job fit; and (7) CDSE partly mediated the relationship between CSCC and subjective well-being. The results contributed to social cognitive career theory model and provided suggestions for both the career educators and consultants.

Keywords: career success, career satisfaction, person-job fit, well-being, career decision-making self-efficacy

\section{INTRODUCTION}

The careers landscape has changed remarkably over the last few decades due to fast-changing employment patterns. Previously, most people developed linear careers within one organization with relatively aligned interests and targets, such as pay raise and promotions, which were considered as objective career success criteria (Stumpf, 2014). Nowadays, the concepts of boundaryless career and protean career have been advanced by the fact that employees play an increasing active role in career development and move voluntarily across organizational boundaries for better employability and career success (Arthur, 1994; Hall, 2002). People pursue jobs that are meaningful to them personally and assess career success more subjectively based on their own standards, needs, values, and aspirations (Arthur and Rousseau, 1996).

As attention turned to subjective career success, Hall and Chandler (2005) reminded scholars to avoid "either-or" discourse: both objective standards and subjective feelings should be considered while assessing career success. Numerous qualitative studies have provided evidence on the multidimensionality of career success. For instance, Gattiker and Larwood (1986) demonstrated 
that career success encompassed job success, personal success, financial success, hierarchical success, and life success. Moreover, Dries et al. (2008) developed a multidimensional model for career success and concluded nine dimensions: performance, advancement, self-development, creativity, security, satisfaction, recognition, cooperation, and contribution. One fact that cannot be ignored is the overlap between objective career success and subjective career success. For instance, income and social status are objective factors in career success, but further assessment of career success is based on subjective insights. Therefore, when discussing the criteria of career success, more attention should be paid to diverse views and personal insights, rather than simply applying universal standards (Mayrhofer et al., 2016).

Combined with qualitative and quantitative methods, Zhou et al. (2013) developed a three-dimensional framework for career success criteria, including fulfillment of intrinsic psychological needs, balance between work and nonwork lives, and extrinsic rewards. Scholars conducted further studies to explore the antecedents and outcomes of career success criteria (e.g., Pan and Zhou, 2013; Zhou et al., 2016). Since career success criteria denote perception, cognition, value, and self-defined goals of one's career, people have different priorities and vary in the degree of recognition of each dimension (Zhou et al., 2016). With different criteria, people will behave differently and choose different career paths. For example, some people work overtime for higher payment; someone earns less to take good care of his or her children; while others build social networks, seeking opportunities for promotion.

There are no right or wrong paths, and all paths lead to success of different sorts. Scholars have offered academic evidence, such as Dyke and Murphy (2006) and Visagie and Koekemoer (2014), who found that individuals with successful careers had distinct success criteria. This means that the content of the criteria does not determine one's career success. However, according to Mayrhofer et al. (2016), career success criteria guide and motivate individuals to develop their careers. Therefore, a crucial question of how career success criteria affect career development has arisen.

From the perspective of the goal-setting theory, the degree of certainty or clarity is a significant concomitant of a goal, determining goal achievement (Locke, 1967). Given that career success criteria denote employees' ultimate career goals (Arthur et al., 2005; Heslin, 2005), this study proposes the concept of career success criteria clarity (CSCC) and attempts to demonstrate the role of such a concept in career development through rigorous empirical testing. It contributes to the existing literature on career success and career development in at least three ways. First, while previous research focused on the content of career success criteria, this research pays more attention to the clarity of career success criteria and provides a new perspective to advance the current understanding in the field of career success. Second, based on the goal-setting theory, it examines the predictive validity of CSCC on crucial careerrelated outcomes, enriching the literature of career development. Third, this research attempts to deepen the understanding of career decision-making self-efficacy (CDSE) by testing its intermediary role in the relationship between CSCC and employment outcomes to complete the social cognitive career theory (SCCT) models.

\section{CAREER SUCCESS CRITERIA CLARITY AND ITS DISTINCTIVENESS FROM RELATED CAREER CONCEPTS}

The relationships between career success criteria and career development outcomes are complicated and have not been well explained (Sortheix et al., 2015). According to the goal-setting theory, vague goals, such as "do one's best," could not lead to the best performance due to an almost complete lack of motivation effect on employees. On the contrary, such a vague goal offers an excuse for those with low performance. Therefore, the clarity of the expected achievement is important (Locke and Latham, 2006), and we assume that CSCC has a crucial impact on career development.

Career success criteria clarity is based on the concept of career success criteria, which are components of the dynamic self-system, a constantly changing combination of self-schemas that represent one's attitude, belief, value, and goal in career development and further guide his or her emotions, information processing and vocational behaviors (Hoyle and Sherrill, 2006; Zhou et al., 2013). While developing careers, people continuously construct their career success criteria (Dries et al., 2008). The better one's career success criteria are constructed, the better clarity the person has for career success criteria. Approximately 30 years ago, Campbell (1990) introduced a new concept in psychology, called self-concept clarity (Campbell, 1990; Campbell and Lavallee, 1993; Campbell et al., 1996). As a structural aspect of self-concept, it refers to the extent to which an individual's self-concept is clearly and confidently defined. The degree of clarity reflects how well the components of self-concept are organized. Similar to self-concept, career success criteria are also viewed as a cognitive schema based on personal values, traits, and self-relevant information (Kihlstrom and Cantor, 1984; Zhou et al., 2013). Hence, we argue that clarity is a key characteristic that is likely to make career success criteria effective in prompting proactive career behaviors. The clarity develops over time as individuals think about goals and aspirations for their careers, observe role models, and consider what they value most in their careers, implying a construction process. We thus propose that the concept of CSCC offers a new perspective for career success studies and advances the current understanding on career success criteria by distinguishing the structure from the contents.

In addition, relevant studies increasingly reveal the importance of clarity in career domain, such as future work self-salience (Strauss et al., 2012; Cai et al., 2015; Taber and Blankemeyer, 2015). Future work self refers to the image of individuals' ideal future working life, while future work self-salience indicates the degree to which the future work self is clear and easy to image (Strauss et al., 2012). Although focusing on a different facet of a career, a point in common between future work self-salience and CSCC is that a clearer career cognition and salient vocational goals can lead to better career development. Both future work self-salience and CSCC 
can motivate vocational behaviors and generate strategies to keep striving toward goals. Future work self-salience is usually measured by a single-dimension scale developed by Strauss et al. (2012). A sample item is "The mental picture of this future is very clear." People vary in generating mental pictures for future working lives. Some may develop general images, such as being an expert on chemistry, while others may have specific images, including detailed career position, job content, and salary level, resulting in high subjectivity. CSCC is distinct from future work self-salience in that career success criteria have a multidimensional structure, which provides a more comprehensive perspective on clarity.

For the reasons mentioned above, the current research focuses on the clarity of career success criteria, which is a structural aspect of career success criteria and is defined as the extent to which the criteria of assessing career success is clearly and confidently constructed. Accordingly, the measurement of CSCC was developed on the basis of the career success criteria scale. The reliability and validity of the measurement were tested with a pilot study which has been published on a Chinese journal with the whole process of developing the scale. The results will be introduced in brief for a better understanding of the current research and to provide an English version of the scale for international scholars. For more details, please refer to Xin et al. (2019). In addition, the main study aims to examine the predictive validity of CSCC on crucial outcomes with an integrated conceptual framework. To be specific, current research has two goals: (1) testing whether CSCC contributes to career satisfaction, person-job fit, and subjective well-being; and (2) examining the mediation effect of CDSE. Overall, two consecutive studies were conducted: the first one examining the validity and reliability of the scale of CSCC and the second study explaining the influences of CSCC on both vocational and life outcomes.

\section{PILOT STUDY - MEASURING CAREER SUCCESS CRITERIA CLARITY}

The pilot study was conducted to develop a measure for CSCC and to test the quality of the items, as well as reliability and validity. Data were collected from three universities in Beijing, China. Permission to conduct this study was obtained from the university ethics boards. The students involved in this research were informed that their personal information would be kept confidential and that all the data would be used only for research purposes. In total, we distributed 300 surveys and received 231 (77\%) responses. The mean age of the participants was 22 years $(\mathrm{SD}=0.96) ; 6.8 \%$ of the participants were freshmen, $20.3 \%$ were sophomores, $51.7 \%$ were juniors, $16.9 \%$ were seniors, and $4.4 \%$ were graduates.

The measure of CSCC considers the individuals' judgment of clarity based on the short version of the career success criteria scale (Pan and Zhou, 2015). As a result, we modified the items measuring career success criteria to measure CSCC. We asked the participants to rate the extent to which they were clear and confident when judging each item of the scale of
TABLE 1 | CR, CITC, EFA outcome of career success criteria clarity's items $(N=231)$.

Career success criteria clarity

\begin{tabular}{|c|c|c|c|}
\hline Items & CR sig. & CITC & $\begin{array}{l}\text { Factor } \\
\text { loadings }\end{array}$ \\
\hline $\begin{array}{l}\text { Whether being continuously promoted to higher } \\
\text { level in an organization represents career success }\end{array}$ & 0.00 & 0.64 & 0.70 \\
\hline $\begin{array}{l}\text { Whether achieving power over an organization } \\
\text { represents career success }\end{array}$ & 0.00 & 0.70 & 0.76 \\
\hline $\begin{array}{l}\text { Whether making much money through work } \\
\text { represents career success }\end{array}$ & 0.00 & 0.75 & 0.81 \\
\hline $\begin{array}{l}\text { Whether one's talents and potential being fully } \\
\text { utilized in career represents career success }\end{array}$ & 0.00 & 0.84 & 0.88 \\
\hline $\begin{array}{l}\text { Whether being happy during work represents } \\
\text { career success }\end{array}$ & 0.00 & 0.82 & 0.86 \\
\hline $\begin{array}{l}\text { Whether being continuously engaged in } \\
\text { challenging work represents career success }\end{array}$ & 0.00 & 0.82 & 0.86 \\
\hline $\begin{array}{l}\text { Whether feeling fulfilled at work represents career } \\
\text { success }\end{array}$ & 0.00 & 0.78 & 0.83 \\
\hline $\begin{array}{l}\text { Whether enjoying life in career represents career } \\
\text { success }\end{array}$ & 0.00 & 0.76 & 0.81 \\
\hline $\begin{array}{l}\text { Whether achieving balance between life and work } \\
\text { represents career success }\end{array}$ & 0.00 & 0.72 & 0.78 \\
\hline $\begin{array}{l}\text { Whether maintaining good physical and mental } \\
\text { health represents career success }\end{array}$ & 0.00 & 0.63 & 0.70 \\
\hline Eigen value & & 6.39 & \\
\hline Cumulative explaining variation (\%) & & 63.93 & \\
\hline
\end{tabular}

CR, critical ratio; CITC, corrected item-total correlation; EFA, exploratory factor analysis.

career success criteria. For example, one of the items measuring career success criteria is "One has achieved power over an organization." We modified this item into "I am clear and confident regarding my views on whether achieving power over an organization represents career success." Students responded on a 7 -point Likert scale ranging from 1 (strongly disagree) to 7 (strongly agree).

As shown in Table 1, 10 items of CSCC all met the standards of CR, CITC, and exploratory factor analysis (EFA) testing, indicating good quality of those items. In addition, our scale had high reliability (Cronbach's $\alpha=0.94$ ) and high discriminant validity $(\mathrm{AVE}=0.59)$.

\section{MAIN STUDY - CONSEQUENCES OF CAREER SUCCESS CRITERIA CLARITY}

The SCCT views value orientations as factors that affect one's career expectations and decisions (Lent et al., 2000). The goalsetting theory also demonstrates that the clarity of goals has direct impact on goal achievement (Locke, 1967). Since career success criteria reflect career-relevant values and denote the ultimate career goals that individuals pursue, we propose that CSCC can positively predict career success and expectations.

Of the 216 research articles on subjective career success in 30 years, $86 \%$ of them used career satisfaction to measure subjective career success ( $\mathrm{Ng}$ and Feldman, 2014). Career 
satisfaction has also been seen as a significant measure of a career as a whole (Gattiker and Larwood, 1988; Gattiker and Larwood, 1989). To be coherent with previous research, we choose career satisfaction as an outcome of CSCC. In the era of boundaryless careers, person-job fit is considered to be a wise choice during extensive interorganizational mobility (Tinsley, 2000), so the effect of CSCC on person-job fit is also tested in this paper. Moreover, the purpose of a career for most people is to pursue a good life, which means a flourishing life with highlevel well-being (Huppert, 2009; Coffey et al., 2016). Therefore, the influence of career success criteria on well-being is also examined in this study.

Overall, the aim of this study is to examine the impact of CSCC on career satisfaction, person-job fit, and subjective wellbeing. Since individuals with clear career success criteria will have more confidence in making career decisions and in turn achieve career success and life goals, we will also examine the mediation role of CDSE in the relationships mentioned above (Dietrich et al., 2013).

\section{Theoretical Background and Hypotheses Development Career Success Criteria Clarity and Career Satisfaction}

Career satisfaction refers to an individual's overall judgment and evaluation of personal career development (Greenhaus et al., 1990). Scholars conducted numerous studies to identify the predictors of career satisfaction, including personal, vocational, and organizational factors, such as gender, personality, and organizational climate (Frank et al., 1999; El Baroudi et al., 2017). Judge et al. (2010) also noticed that a high level of core self-evaluation could motivate employees to shoulder more responsibility and achieve improved performance, in turn leading to heightened career satisfaction. Similar to core self-evaluation, CSCC represents an individual's self-cognition and values in a career. A high degree of CSCC would motivate employees to make progress in career development, such as participating in challenging or extra tasks, which are beneficial to achieving career goals, resulting in high rewards and career satisfaction.

According to the goal-setting theory, the clarity of goals has a direct impact on goal achievement (Locke, 1967). When individuals have more clarity on career success criteria, they tend to have a stronger perception of their current career development and pursue career success proactively, and in turn gain career satisfaction. Therefore, as a personal attribute for careers, we expect CSCC would influence career satisfaction. Consequently, we propose the following hypothesis:

$\mathrm{H} 1$ : CSCC is positively related to career satisfaction.

\section{Career Success Criteria Clarity and Person-Job Fit}

Person-job fit is defined as the consistency or the degree of matching between an individual's characteristics and those of the job or tasks that are performed at work (Lee et al., 2010). In the past, most people developed their careers within one organization, so they took organizations into account foremost when making career choices. However, with the advent of boundaryless careers, people now pay more attention to their personal requirements and job features, such as the salary package, job duties, and promotion opportunities. Thus, personjob fit is considered to be a wise career choice (Tinsley, 2000). Many studies indicate that person-job fit should take two aspects into consideration. On the one hand, specific knowledge and employee skills should be matched with their job requirements, namely, demands-abilities fit. On the other hand, employees' needs and desires should fit with their jobs, namely, needssupplies fit (Ardiç et al., 2016). High-level person-job fit means that the job satisfies the employee's needs, capacities, and values, which further contributes to his or her career development.

Previous research has revealed the positive effects of person-job fit on organizational citizenship behavior and job performance and the negative impact on turnover intention (Hassan et al., 2012; Lin et al., 2014). Therefore, person-job fit is an essential goal in job searching and occupational mobility. According to the goal-setting theory, individuals tend to realize their aspirations more easily when their visions are clearer (Locke et al., 1968). Clear career success criteria are motivational resources because they support the process through which vocational goals are clearly defined and strategies are generated for achieving these goals (Strauss et al., 2012). Individuals with a high level of CSCC tend to have a better understanding of what skills should be equipped and reduce role ambiguity, improving demand-ability fit (Cai et al., 2018). They will also have a better understanding of what they want from their jobs, promoting need-supply fit (Dietrich et al., 2013). In this case, they are more capable to find suitable jobs. Consequently, we propose the following hypothesis:

\section{$\mathrm{H} 2$ : CSCC is positively related to person-job fit.}

\section{Career Success Criteria Clarity and Well-Being}

How to gain well-being through career development is becoming an interest of researchers and practitioners. Some believe that one way to achieve well-being is to strive for career success (Diener and Seligman, 2004). However, the relationship between career success and well-being is complicated, a position supported by both practical and academic evidence. For one thing, high income and high status-position with power may increase personal wellbeing. For another, time constraints, stress, and other costs may impair life satisfaction. The famous paradox of happiness stems from the discussion of the relationship between income and wellbeing (Easterlin, 2001).

Apart from inconsistent results, most scholars focus on the relationship between career outcomes and well-being, neglecting the influence of vocational cognition and values on happiness. Career success criteria not only denote ultimate career values and goals that individuals pursue but also reflect values and goals of one's own view of life. For example, the work-life balance dimension of career success criteria expresses the goal of acquiring balance between work and nonwork life. The fundamental reason is that career and life are inalienable, as career is a process through which people endow meanings to their vocations (Savickas, 2013). As a result, it is integral to discuss the impact of CSCC on both career and life outcomes. 
Moreover, drawing upon the goal-setting theory, goals are easier to achieve when they are set more clearly (Locke, 1967). When individuals have a clear picture of what they are pursuing for career success and their whole lives, they will endeavor to achieve their goals by improving workrelated abilities and advancing career plans accordingly. This process generates a sense of control and security over a career, enhancing their overall sense of well-being. A high level of CSCC, representing one's self-confidence and clarity regarding career success, can regulate employees' psychological process and reduce their negative feelings, further ensuring their subjective well-being (Liu et al., 2016). Consequently, we propose the following hypothesis:

H3: CSCC is positively related to well-being.

\section{The Mediation Role of Career Decision-Making Self-Efficacy}

Lent et al. (1994, 2000) have developed the SCCT to offer a unifying framework for explaining how people generate vocational interests, make relevant choices, and pursue positive vocational outcomes. It posits that personal traits primarily affect individuals' self-efficacy beliefs and further contribute to career development and vocational performance (Brown et al., 2011). As a crucial component in the SCCT model, self-efficacy represents an individual's confidence in his or her abilities to accomplish tasks (Hackett and Betz, 1981). In the field of career development, CDSE refers to one's belief that he or she can successfully complete the tasks which are necessary for making career decisions, compassing five dimensions: selfappraisal, occupational information, goal selection, planning, and problem solving (Betz et al., 1996). Many studies have demonstrated that CDSE serves as an important indicator of individuals' vocational behaviors and outcomes, such as job satisfaction (Caprara et al., 2003; Peng and Mao, 2015; Li et al., 2017), intrinsic satisfaction (Borgogni et al., 2013), and career choice commitment (Jin et al., 2009). According to SCCT, career-related expectations and decisions are influenced by personal and contextual factors (Brown et al., 2011). Personality and other social variables (e.g., race, gender, certainty, extraversion, conscientiousness, and cultural mistrust) have been shown to have significant correlations with CDSE (BullockYowell et al., 2011). Representing clear vocational goals and relevant cognition, CSCC enables individuals to generate more accurate self-appraisal and gain occupational information more effectively. They will be confident to make career decisions and prepare for the future. Thus, we suppose that CSCC would contribute to a high level of CDSE. Moreover, individuals with a high level of self-efficacy are motivated to strive for their goals (Bandura, 1977). They are inclined to adopt a problem-focused coping style and seek for external resources like social support (Chang and Edwards, 2015). They are more capable of dealing with challenges and solving difficult problems (Liu et al., 2016), ensuring a high level of career satisfaction, person-job fit, and subjective well-being. Therefore, our study sought to examine the mediating effect of CDSE in the relationships between CSCC and career satisfaction,

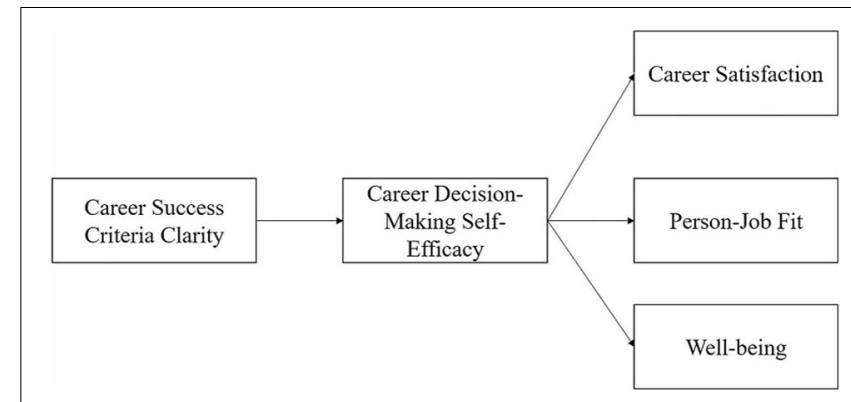

FIGURE 1 | Research model.

person-job fit, and well-being. Consequently, we propose the following hypotheses:

H4: CDSE mediates the relationship between CSCC and career satisfaction.

H5: CDSE mediates the relationship between CSCC and person-job fit.

H6: CDSE mediates the relationship between CSCC and well-being.

Combining all the hypotheses, we propose a mediation model to test the relationships between CSCC and career satisfaction, person-job fit, and well-being with CDSE as a mediator. Figure 1 shows the research model.

\section{Samples and Procedures}

Since the early stages of a career are critical for the formation of career values and cognition, the rapid change of employment models brings more challenges and difficulties to young people as they establish careers (Sortheix et al., 2015). Therefore, we particularly focus on employees in their early career stages in this research. The data come from the on-job graduate students of a university in Beijing and previous graduates of a college in Taiyuan, China. We distributed questionnaires via e-mail, and a total of 240 usable sets of questionnaires were obtained out of 500, yielding an overall response rate of $48 \%$. All the participants held a bachelor's degree. Part of them began to work with no further education after undergraduate period. Others were on-the-job graduates. Among the participants, $80.40 \%$ were women, and the average age of the respondents was 26.92 years $(\mathrm{SD}=3.92)$.

\section{Measures}

The scales used in this study were developed originally in English. Following recommended procedures (Brislin, 1980), we translated them into Chinese. Then, we back translated the Chinese versions of those scales into English. We invited two doctoral students majoring in English to compare original versions with the back translations. According to their suggestions, we modified a few items to ensure accuracy and clarity. 


\section{Career Success Criteria}

Career success criteria were measured with the short version of 10 items developed by Pan and Zhou (2015). This scale was used in previous studies and had good validity (Zhou et al., 2016). Participants were asked to rate the extent to which they agree is appropriate to assess career success as a criterion on a 7-point Likert scale ranging from 1 (strongly disagree) to 7 (strongly agree). For instance, "Career success means that one's talents and potential capacities are fully utilized in his or her career." Cronbach's alpha for the scale was 0.90 .

\section{Career Success Criteria Clarity}

To assess CSCC, we asked the participants to rate the extent to which they were clear and confident while making judgment on each item of the scale of career success criteria. A sample item was "I am clear and confident regarding my views on whether achieving power over an organization represents career success." Students responded on a 7-point Likert scale ranging from 1 (strongly disagree) to 7 (strongly agree). Cronbach's alpha for the scale was 0.94 .

\section{Career Decision-Making Self-Efficacy}

To assess self-efficacy in career decision-making, the scale of 25 items developed by Betz et al. (1996) was used. This scale was used in previous research and had good validity (Chung, 2002; Zhou et al., 2016). A sample item was "Choose a major or career that will fit your interests." Participants rated their confidence on decision-making tasks on a 7-point Likert scale ranging from 1 (not confident at all) to 7 (extremely confident). Cronbach's alpha for the scale was 0.97 .

\section{Career Satisfaction}

Career satisfaction was measured with a widely used scale developed by Greenhaus et al. (1990). This scale was validated by previous studies (Seibert et al., 1999). A sample item was "I am satisfied with the success I have achieved in my career." Participants responded to five items on a 7-point Likert scale ranging from 1 (strongly disagree) to 5 (strongly agree). Cronbach's alpha for the scale was 0.92 .

\section{Person-Job Fit}

We used the four-item scale adopted from Saks and Ashforth (1997) to measure the level of fit between employee and his or her current work. This scale was validated by previous studies (Carless, 2005). An example of the items used was "To what extent do your knowledge, skills and abilities match the requirements of the job." The Cronbach's alpha for this scale was 0.87 .

\section{Well-Being}

In this study, we use the positive emotion subscale of PANAS (Positive and Negative Affect Schedule; Watson et al., 1988) to measure well-being following previous studies (Pan and Zhou, 2015; Pan et al., 2016). This scale contains 10 items assessing positive affect throughout the past few weeks, involving attentive, active, alert, determined, excited, enthusiastic, inspired, proud, interested, and strong. Each item was rated on a 5-point Likert scale ranging from 1 (very slightly or not at all) to 5 (extremely).
This scale was validated by previous studies (Pan and Zhou, 2015; Pan et al., 2016). The Cronbach's alpha in this study was 0.85 .

\section{Control Variables}

We controlled for the effects of gender and age. On the basis of previous studies, frequently used control variables in research concerning to career success, well-being, and career satisfaction included age, gender, educational background, and career stages (Judge and Bretz, 1994; Stumpf, 2014; Zhou et al., 2016; Batz and Tay, 2018). This study focused on employees in their early careers, and all the participants graduated with a bachelor's degree and no subsequent graduate degree. As a result, only gender and age were controlled in this study.

\section{RESULTS}

\section{Common Method Bias Test}

This study adopted a self-report method to collect data. Therefore, we used Harman's single-factor test to address the issue of common method bias according to Podsakoff and Organ (1986). We loaded all the items into an exploratory factor test and examined the unrotated factor solution (Podsakoff et al., 2003). The result of exploratory factor analysis in this study showed that the first factor accounts for $30.59 \%$ of total variance. No one factor accounted for the majority of the covariance among the measures. Therefore, common method bias was not a problem in this study.

To further validate this result, we also applied confirmatory factor test following previous studies (e.g., Korsgaard and Roberson, 1995; Iverson and Maguire, 2000). As shown in Table 2, single-factor model indices were worse than those of the six-factor model, supporting the result of exploratory factor test.

\section{The Measurement Model}

In this study, we used confirmatory factor analysis (CFA) to test the discriminant validity of the measurement model. KMO test and the Bartlett's test of sphericity were conducted before CFA. The KMO value was 0.82 , and the result of Bartlett's test sphericity was significant $(p<0.001)$. Therefore, this sample was suitable for factor analysis (Hair et al., 1995).

We used several fit indices to evaluate the fitness of the model according to established practice (Hu and Bentler, 1999; Byrne, 2013), including $\chi^{2} / \mathrm{df}$, Comparative Fit Index (CFI), TuckerLewis Index (TLI), and root mean square error of approximation (RMSEA). The results of the CFA were shown in Table 2. The measurement model fit with the data best than other models with $\chi^{2} / \mathrm{df}=2.03, \mathrm{CFI}=0.93$, TLI $=0.92$, and $\mathrm{RMSEA}=0.07$ (Table 2). Distinctiveness of the measurement model in this study was ensured.

\section{Descriptive Statistics}

As shown in Table 3, career satisfaction is positively related to CSCC ( $r=0.44, p<0.01)$, supporting Hypothesis 1 . Person-job fit is positively correlated to CSCC $(r=0.34, p<0.01)$, supporting Hypothesis 2. Well-being is positively related to CSCC $(r=0.34$, 
TABLE 2 | Model comparison.

\begin{tabular}{|c|c|c|c|c|c|c|c|c|}
\hline Model & $x^{2}$ & $d f$ & $\chi^{2} / d f$ & RMSEA & CFI & TLI & $\Delta \chi^{2}$ & $\Delta d f$ \\
\hline Six-factor Model & 976.22 & 480 & 2.03 & 0.07 & 0.93 & 0.92 & & \\
\hline Five-factor Model & $1,101.20$ & 485 & 2.27 & 0.07 & 0.91 & 0.90 & $124.98^{\star \star \star}$ & 5 \\
\hline Four-factor Model-1 & $1,537.74$ & 489 & 3.15 & 0.10 & 0.85 & 0.84 & $561.52^{\star \star \star}$ & 9 \\
\hline Four-factor Model-2 & $1,467.54$ & 489 & 3.00 & 0.09 & 0.86 & 0.85 & $491.32^{\star \star \star}$ & 9 \\
\hline Three-factor Model & $1,894.56$ & 492 & 3.85 & 0.11 & 0.80 & 0.78 & $918.33^{\star \star *}$ & 12 \\
\hline Two-factor Model & $3,166.29$ & 494 & 6.41 & 0.15 & 0.62 & 0.59 & $2,190.07^{\star \star \star}$ & 14 \\
\hline Single-factor Model & $3,596.34$ & 495 & 7.27 & 0.16 & 0.55 & 0.52 & $2,620.12^{\star \star \star}$ & 15 \\
\hline
\end{tabular}

${ }^{* * *} p<0.001$. Five-factor Model: Career success criteria clarity (CSCC) + Career success criteria, Career decision-making self-efficacy (CDSE), Career satisfaction,

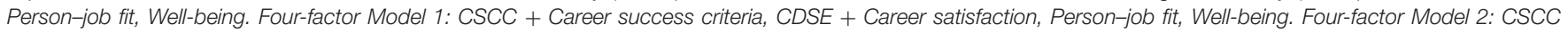

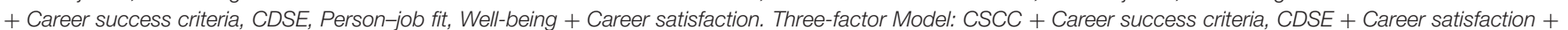

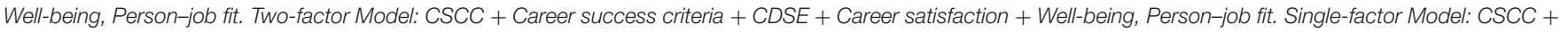

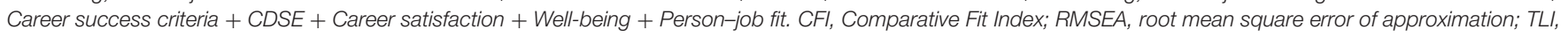
Tucker-Lewis Index.

TABLE 3 | Means, standard deviation, and correlations for variables $(N=240)$.

\begin{tabular}{|c|c|c|c|c|c|c|c|c|c|}
\hline Variables & Means & SD & 1 & 2 & 3 & 4 & 5 & 6 & 7 \\
\hline 1. Gender & 1.82 & 0.38 & - & & & & & & \\
\hline 2. Age & 26.92 & 3.92 & 0.08 & - & & & & & \\
\hline 3. Career success criteria clarity & 4.84 & 1.04 & 0.07 & 0.01 & - & & & & \\
\hline 4. Career decision-making self-efficacy & 4.81 & 1.13 & 0.03 & 0.00 & $0.48^{* *}$ & - & & & \\
\hline 5. Career satisfaction & 4.72 & 1.30 & 0.04 & 0.04 & $0.44^{\star \star}$ & $0.72^{\star \star}$ & - & & \\
\hline 6. Person-job fit & 3.66 & 0.81 & 0.07 & 0.02 & $0.34^{\star \star}$ & $0.69^{\star \star}$ & $0.63^{\star \star}$ & - & \\
\hline 7. Well-being & 4.58 & 1.20 & -0.07 & 0.02 & $0.34^{\star *}$ & $0.39^{\star \star}$ & $0.36^{\star \star}$ & $0.37^{\star \star}$ & - \\
\hline
\end{tabular}

${ }^{* *} p<0.01$.

$p<0.01)$, supporting Hypothesis 3. CDSE is positively related to $\operatorname{CSCC}(r=0.48, p<0.01)$.

\section{The Structural Model}

Since our model includes multiple dependent variables and mediator, we used structural equation modeling to analyze the whole model simultaneously. As shown in Table 4, M3 is significantly better than other models. Results are shown in Figure 2, which support Hypothesis 4, Hypothesis 5, and Hypothesis 6.

\section{Bootstrapping Results of Mediation Effects}

To further confirm the mediation effects of CDSE, this study adopted the biased-corrected bootstrapping method developed

TABLE 4 | Structural equation modeling comparison.

\begin{tabular}{lcccccccc}
\hline Model & $\chi^{\mathbf{2}}$ & $\boldsymbol{d} \boldsymbol{f}$ & $\chi^{\mathbf{2}} / \boldsymbol{d f}$ & RMSEA & CFI & TLI & $\boldsymbol{\Delta} \chi^{\mathbf{2}}$ & $\boldsymbol{\Delta} \boldsymbol{d f}$ \\
\hline M0 & 731.80 & 395 & 1.85 & 0.06 & 0.93 & 0.93 & & \\
M1 & 731.64 & 394 & 1.86 & 0.06 & 0.93 & 0.93 & 0.16 & 1 \\
M2 & 731.69 & 394 & 1.86 & 0.06 & 0.93 & 0.92 & 0.11 & 1 \\
M3 & 716.80 & 394 & 1.82 & 0.06 & 0.93 & 0.93 & $15.00^{\star \star *}$ & 1
\end{tabular}

${ }^{* * *} p<0.001 . M 1$ adds a direct path from career success criteria clarity (CSCC) to career satisfaction based on MO; M2 adds a direct path from CSCC to person-job fit based on MO; M3 adds a direct path from CSCC to well-being based on MO. CFI, Comparative Fit Index; RMSEA, root mean square error of approximation; TLI, Tucker-Lewis Index. by Preacher and Hayes (2008). Table 5 showed the results of mediation model, and Table 6 showed the result of indirect effects. In Table 5, equation 1 showed the results of the total effect model. Equations 2 and 3 showed the results of mediation model.

As the result of equation 1 showed, CSCC had a significantly positive effect on career satisfaction $(\beta=0.49, p<0.001)$, personjob fit $(\beta=0.25, p<0.001)$, and well-being $(\beta=0.49, p<0.001)$. These results provided further support for Hypotheses 1, 2, and 3. In equation 2 , the positive effects of CSCC on CDSE were all significant (career satisfaction: $\beta=0.49, p<0.001$; personjob fit: $\beta=0.48, p<0.001$; well-being: $\beta=0.49, p<0.001$ ). In equation 3 , only CDSE positively predicted career satisfaction

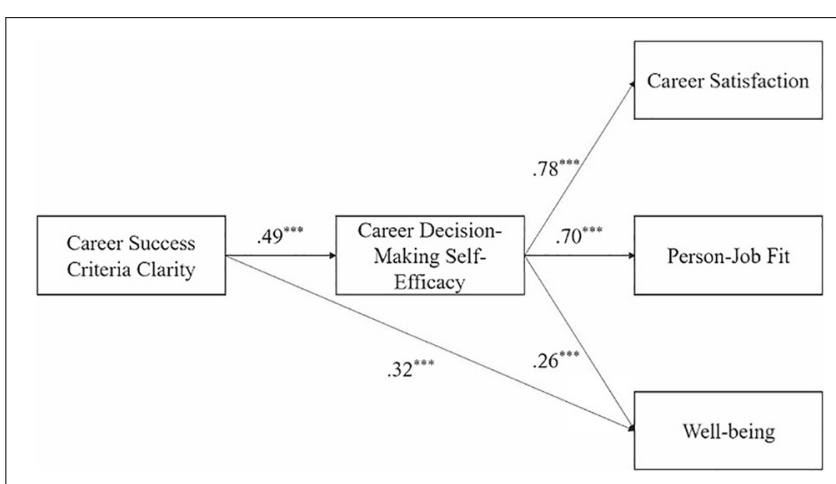

FIGURE 2 | Result of research model test. 
TABLE 5 | Results of mediation model $(N=240)$.

\begin{tabular}{|c|c|c|c|c|c|c|c|c|c|c|}
\hline \multirow[t]{2}{*}{ Dependent variables } & \multirow[t]{2}{*}{ Variables } & \multicolumn{3}{|c|}{ Equation 1 Total effect } & \multicolumn{3}{|c|}{ Equation 2 OV: CDSE } & \multicolumn{3}{|c|}{ Equation 3 OV: CS/PJF/WB } \\
\hline & & $\beta$ & SE & $t$ & B & SE & $t$ & $\beta$ & SE & $t$ \\
\hline \multirow[t]{6}{*}{ Career satisfaction } & Gender & 0.03 & 0.20 & 0.16 & 0.03 & 0.17 & 0.20 & 0.01 & 0.15 & 0.04 \\
\hline & Age & 0.04 & 0.08 & 0.46 & -0.02 & 0.07 & -0.30 & 0.06 & 0.06 & 0.90 \\
\hline & CSCC & 0.49 & 0.08 & $6.08^{\star \star \star}$ & 0.49 & 0.07 & $7.46^{\star \star \star}$ & 0.08 & 0.07 & 1.25 \\
\hline & CDSE & & & & & & & 0.83 & 0.06 & $13.26^{\star \star \star}$ \\
\hline & $R^{2}$ & 0.15 & & & 0.21 & & & 0.54 & & \\
\hline & $F$ & $12.74^{\star \star \star}$ & & & $19.06^{\star \star \star}$ & & & $61.46^{\star \star \star}$ & & \\
\hline \multirow[t]{6}{*}{ Person-job fit } & Gender & 0.13 & 0.13 & 1.01 & 0.06 & 0.17 & 0.33 & 0.11 & 0.11 & 1.01 \\
\hline & Age & 0.00 & 0.05 & 0.07 & -0.01 & 0.07 & -0.21 & 0.01 & 0.04 & 0.25 \\
\hline & CSCC & 0.25 & 0.05 & $4.79^{\star \star \star}$ & 0.48 & 0.07 & $7.35^{\star \star \star}$ & 0.02 & 0.05 & 0.36 \\
\hline & CDSE & & & & & & & 0.47 & 0.04 & $11.08^{\star * \star}$ \\
\hline & $R^{2}$ & 0.11 & & & 0.21 & & & 0.44 & & \\
\hline & $F$ & $8.67^{\star \star \star}$ & & & $18.70^{\star \star \star}$ & & & $40.94^{\star \star \star}$ & & \\
\hline \multirow[t]{6}{*}{ Well-being } & Gender & -0.37 & 0.20 & -1.88 & 0.03 & 0.17 & 0.17 & -0.38 & 0.19 & $-1.97 *$ \\
\hline & Age & 0.02 & 0.08 & 0.24 & -0.01 & 0.07 & -0.19 & 0.02 & 0.08 & 0.29 \\
\hline & CSCC & 0.49 & 0.08 & $6.38^{\star \star \star}$ & 0.49 & 0.07 & $7.47^{\star \star \star}$ & 0.35 & 0.08 & $4.17^{\star \star \star}$ \\
\hline & CDSE & & & & & & & 0.29 & 0.08 & $3.63^{\star \star \star}$ \\
\hline & $R^{2}$ & 0.17 & & & 0.21 & & & 0.22 & & \\
\hline & $F$ & $13.91^{\star \star \star}$ & & & $19.08^{\star \star \star}$ & & & $14.32^{\star \star \star}$ & & \\
\hline
\end{tabular}

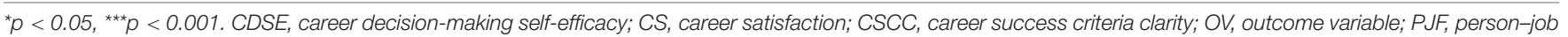
fit; WB, well-being.

$(\beta=0.83, p<0.001)$ and person-job fit $(\beta=0.47, p<0.001)$, while both CSCC and CDSE positively predicted well-being ( $\beta=0.35, p<0.001 ; \beta=0.29, p<0.001$, respectively), illustrating that: (1) CDSE fully mediated the relationship between CSCC and career satisfaction, (2) CDSE fully mediated the relationship between CSCC and person-job fit, and (3) CDSE partly mediated the relationship between CSCC and well-being. In Table 6, 95\% confidence interval of CDSE on these three dependent variables did not include 0. Therefore, Hypotheses 4, 5, and 6 were further supported.

\section{DISCUSSION}

This study proposes a new concept of CSCC, enriching the literature of career success. Previous studies have mainly focused on the content of career success criteria, while our study explores the structural aspect of career success criteria from a constructive perspective. The development of CSCC scale provides an instrument for future studies and offers an evaluation tool for individuals and organizations to diagnose career obstacles and manage career development.

TABLE 6 | Results of indirect effect $(N=240)$.

\begin{tabular}{lcccc}
\hline Dependent variables & $\boldsymbol{\beta}$ & SE & LLCI & ULCI \\
\hline Career satisfaction & 0.40 & 0.07 & 0.27 & 0.53 \\
Person-job fit & 0.23 & 0.04 & 0.15 & 0.32 \\
Well-being & 0.14 & 0.07 & 0.03 & 0.30 \\
\hline
\end{tabular}

$\mathrm{LLCl}$, lower limit of the $\mathrm{Cl}$; ULCl, upper limit of the $\mathrm{Cl}$.
Drawing on the goal-setting theory, we construct a conceptual model to test the predictive effect of CSCC on career satisfaction, person-job fit, and well-being through the mediation role of CDSE. For careers, our study provides empirical evidence for the positive effect of CSCC on career satisfaction and person-job fit. Although numerous studies have explored the antecedents of career satisfaction, most of them emphasized the internal attributes of career management, ignoring the proactivity of individuals (Magee, 2013). Since CSCC is the degree to which individuals construct their career success criteria, this indicator reflects individuals' proactivity and contributes to career satisfaction studies. Besides, the significant predictive role of CSCC on person-job fit has also been well examined in this study. People with better understanding of what they want from their jobs are more capable of finding suitable jobs.

Apart from vocational outcomes, CSCC was also proved to be a fundamental explanation of well-being. Diener and Seligman (2004) point out that career success is an important source of well-being, and many studies discuss the relationship between career success and well-being. However, they focus more on the outcomes or feelings of career success, ignoring the cognition and values underlying career success. Our study reinforces the significance of vocational cognition and values in generating overall well-being. In general, the results illustrate that CSCC influences not only vocational outcomes but also overall well-being.

This study also reveals the underlying mechanism between CSCC and the outcomes above by examining the mediation role of CDSE, expanding the SCCT model (Lent et al., 2000). Previous research shows that personality and some social variables have significant correlations with CDSE (Bullock-Yowell et al., 2011). 
This study contributes to academic literature by proving that individuals with clear vocational goals and relevant cognition could generate more accurate self-appraisals and gain occupational information more effectively. Consequently, they will be more confident to make career choices and therefore gain positive outcomes.

Most of the studies regarding decision-making self-efficacy take SCCT (Lent et al., 1994; Lent et al., 2000) as their theoretical basis (e.g., Gushue and Whitson, 2006). However, we also use the goal-setting theory to explain the relationships mentioned above in our study. Locke and Latham (2006) believe that "the success of goal setting depends upon taking account of the mediators and moderators that determine its efficacy and applicability" (p. 268). In response to their call, this study examined the mediating effect of CDSE. Moreover, this research is in line with Locke and Latham (2006) in exploring the linkage between goals and cognition, namely, the relationship between career satisfaction, person-job fit, well-being, and CSCC.

This study offers crucial practical implications for both employees and organizations. First, the measurement we developed in this study could be adopted by employees to identify their priorities and career goals, aiding in the choice of appropriate strategies in career self-management. Meanwhile, organizations can also gain a better understanding of employees with this instrument and provide effective incentive and career development planning. Second, as CSCC positively affects careerrelated outcomes and subjective well-being, career educators and counselors should attend to the clarity of career success criteria when designing programs or interventions for employees, especially the job market entrants. They could encourage individuals to think about goals and aspirations for their career as well as providing role models to guide them to improve their clarity in career success criteria. As a result, employees can achieve better employment status and gain well-being on the one hand and organizations can retain the talents more efficiently by increasing their career satisfaction on the other. Moreover, as CSCC plays a foundational role in career development by promoting CDSE, career educators and counselors should also be aware that developing individuals' career success criteria is an effective way to facilitate the career decision-making process and further leads to superior employment outcomes.

This study has several limitations. First, since the design of this study cannot support any causal conclusions for the relationships between these variables, further research should adopt a more rigorous design, such as a longitudinal design, to test causal effects. Second, as the mediation model revealed in this study was based on a sample of employees at an early career stage, whether this model can be supported with samples of employees in middle

\section{REFERENCES}

Ardıç, K., Uslu, O., Oymak, Ö, Özsoy, E., and Özsoy, T. (2016). Comparing person organization fit and person job fit. J. Econ. Manage 25, 5-13. doi: 10.22367/jem. 2016.25.01

Arthur, M. B. (1994). The boundaryless career: a new perspective for organizational inquiry. J. Organ. Behav. Spec. Issue Boundar. Career 15, 295-306. doi: 10.1002/ job.4030150402 to late career stages awaits future examinations. Additionally, whether further extension of this model to other outcomes remains to be discovered. Furthermore, we advocate for further research to discover moderators that would strengthen the effects of CSCC on employment outcomes.

Overall, we believe that the construction of career success criteria is crucial due to representation of the cognition and values in career goals, which results in high career satisfaction, person-job fit, and well-being through CDSE.

\section{DATA AVAILABILITY STATEMENT}

The raw data supporting the conclusions of this article will be made available by the authors, without undue reservation, to any qualified researcher.

\section{ETHICS STATEMENT}

An ethics approval was not required according to the guidelines of the Renmin University of China and Beijing University of Chemical Technology as well as national regulations. The principals of the universities supported this research. We sent online questionnaire links to participants. They were informed that their personal information would be kept confidential, and the data would be used only for research purposes. Participants volunteered to take the survey, and they were completely free to quit.

\section{AUTHOR CONTRIBUTIONS}

In preparing this manuscript, LX and WZ worked together to propose a research topic and develop a theoretical model. LX collected data and drafted the manuscript. WZ and FT participated in the discussion on the research model and helped draft the manuscript. ML improved the Introduction, Hypotheses Development, and Discussion sections. All authors read and approved the final manuscript.

\section{FUNDING}

This study is funded by the National Natural Science Fund of China (NSFC) under contract no. 71532003, the Fundamental Research Funds for the Central Universities under contract no. ZY1926, and the China Postdoctoral Science Foundation under contract no. 2019M660429.

Arthur, M. B., Khapova, S. N., and Wilderom, C. P. M. (2005). Career success in a boundaryless career world. J. Organ Behav. Spec. Issue Reconceptual. Career Succ. 26, 177-202. doi: 10.1002/job.290

Arthur, M. B., and Rousseau, D. M. (1996). The Boundaryless Career. New York, NY: Oxford University Press.

Bandura, A. (1977). Self-efficacy: toward a unifying theory of behavioral change. Psychol. Rev. 84, 191-215. doi: 10.1037/0033-295X.84. 2.191 
Batz, C., and Tay, L. (2018). Gender Differences in Subjective Well-Being. Handbook of Well-Being. Salt Lake City, UT: DEF.

Betz, N. E., Klein, K. L., and Taylor, K. M. (1996). Evaluation of a short form of the career decision-making self-efficacy scale. J. Career Assess. 41, 47-57. doi: $10.1177 / 106907279600400103$

Borgogni, L., Russo, S. D., Miraglia, M., and Vecchione, M. (2013). The role of selfefficacy and job satisfaction on absences from work. Eur. Rev. Appl. Psychol. 63, 129-136. doi: 10.1016/j.erap.2012.08.007

Brislin, R. W. (1980). "Translation and content analysis of oral and written material," in Handbook of Cross-Cultural Psychology, eds H. C. Triandis, and J. W. Berry (Boston, MA: Allyn \& Bacon), 398-444.

Brown, S. D., Lent, R. W., Telander, K., and Tramayne, S. (2011). Social Cognitive Career Theory, Conscientiousness, and Work Performance: A Meta-Analytic Path Analysis. J. Vocat. Behav. 79, 81-90. doi: 10.1016/j.jvb.2010.11.009

Bullock-Yowell, E., Andrews, L., and Buzzetta, M. E. (2011). Explaining career decision-making self-efficacy: personality, cognitions, and cultural mistrust. Career Dev. Q 59, 400-411. doi: 10.1002/j.2161-0045.2011.tb00967.x

Byrne, B. M. (2013). Structural Equation Modeling with Mplus: Basic Concepts, Applications, and Programming. New York, NY: Routledge.

Cai, D., Cai, Y., Sun, Y., and Ma, J. (2018). Linking empowering leadership and employee work engagement: The effects of person-job fit, person-group fit, and proactive personality. Front. Psychol 9:1304. doi: 10.3389/fpsyg.2018.01304

Cai, Z., Guan, Y., Li, H., Shi, W., Guo, K., Liu, Y., et al. (2015). Self-esteem and proactive personality as predictors of future work self and career adaptability: an examination of mediating and moderating processes. J. Vocat. Behav. 86, 86-94. doi: 10.1016/j.jvb.2014.10.004

Campbell, J. D. (1990). Self-esteem and clarity of the self-concept. J. Pers. Soc. Psychol. 59, 538. doi: 10.1037/0022-3514.59.3.538

Campbell, J. D., and Lavallee, L. F. (1993). "Who am I? The role of self-concept confusion in understanding the behavior of people with low self-esteem," in Plenum series in social/clinical psychology. Self-esteem: The puzzle of low selfregard, ed. R. F. Baumeister (New York, NY: Plenum Press), 3-20. doi: 10.1007/ 978-1-4684-8956-9_1

Campbell, J. D., Trapnell, P. D., Heine, S. J., Katz, I. M., Lavallee, L. F., and Lehman, D. R. (1996). Self-concept clarity: measurement, personality correlates, and cultural boundaries. J. Pers. Soc. Psychol. 70, 141-156. doi: 10.1037/0022-3514. 70.1 .141

Caprara, G. V., Barbaranelli, C., Borgogni, L., and Steca, P. (2003). Efficacy beliefs as determinants of teachers' job satisfaction. J. Educ. Psychol. 95, 821. doi: 10.1037/0022-0663.95.4.821

Carless, S. A. (2005). Person-job fit versus person-organization fit as predictors of organizational attraction and job acceptance intentions: A longitudinal study. J. Occup. Organ. Psych. 78, 411-429. doi: 10.1348/096317905x25995

Chang, Y., and Edwards, J. K. (2015). Examining the relationships among selfefficacy, coping, and job satisfaction using social career cognitive theory: An SEM analysis. J. Career Assess. 23, 35-47. doi: 10.1177/1069072714523083

Chung, Y. (2002). Career decision-making self-efficacy and career commitment: Gender and ethnic differences among college students. J. Career Dev. 28, 277-284. doi: 10.1023/A:1015146122546

Coffey, J. K., Wray-Lake, L., Mashek, D., and Branand, B. (2016). A multistudy examination of well-being theory in college and community samples. J. Happiness Stud. 17, 187-211. doi: 10.1007/s10902-014-9590-8

Diener, E. (2000). Subjective well-being: the science of happiness and a proposal for a national index. Am. Psychol. 55, 34. doi: 10.1037/0003-066X.55.1.34

Diener, E., and Ryan, K. (2009). Subjective well-being: A general overview. S. Afr. J. Psychol. 39, 391-406. doi: 10.1177/008124630903900402

Diener, E., and Seligman, M. E. (2004). Beyond money: toward an economy of well-being. Psychol. Sci. Publ. Int. 5, 1-31. doi: 10.1111/j.0963-7214.2004.0050 1001.x

Diener, E., Suh, E. M., Lucas, R. E., and Smith, H. L. (1999). Subjective well-being: three decades of progress. Psychol. Bull. 125, 276. doi: 10.1037/0033-2909.125. 2.276

Dietrich, J., Shulman, S., and Nurmi, J. E. (2013). Goal pursuit in young adulthood: the role of personality and motivation in goal appraisal trajectories across 6 years. J. Res. Pers. 47, 728-737. doi: 10.1016/j.jrp.2013.06.004

Dries, N., Pepermans, R., and Carlier, O. (2008). Career success: constructing a multidimensional model. J. Vocat. Behav. 73, 254-267. doi: 10.1016/j.jvb.2008. 05.005
Dyke, L. S., and Murphy, S. A. (2006). How we define success: a qualitative study of what matters most to women and men. Sex Roles 55, 357-372. doi: 10.1007/ s11199-006-9091-2

Easterlin, R. A. (2001). Income and happiness: towards a unified theory. Econ. J. 11, 465-484. doi: 10.1111/1468-0297.00646

El Baroudi, S., Fleisher, C., Khapova, S. N., Jansen, P., and Richardson, J. (2017). Ambition at work and career satisfaction. Career Dev. Int. 22, 87-102. doi: 10.1108/cdi-07-2016-0124

Frank, E., Mcmurray, J. E., Linzer, M., and Elon, L. (1999). Career satisfaction of us women physicians: results from the women physicians' health study. Arch. Intern. Med. 159, 1417. doi: 10.1001/archinte.159.13.1417

Fredrickson, B. L., Cohn, M. A., Coffey, K. A., Pek, J., and Finkel, S. M. (2008). Open hearts build lives: positive emotions, induced through loving-kindness meditation, build consequential personal resources. J. Pers. Soc. Psychol. 95, 1045. doi: $10.1037 / \mathrm{a} 0013262$

Gattiker, U. E., and Larwood, L. (1986). Subjective career success: a study of managers and support personnel. J. Bus. Psychol. 1, 78-94. doi: 10.1007/ BF01018805

Gattiker, U. E., and Larwood, L. (1988). Predictors for managers' career mobility, success, and satisfaction. Hum. Relat. 41, 569-591. doi: 10.1177/ 001872678804100801

Gattiker, U. E., and Larwood, L. (1989). Career success, mobility and extrinsic satisfaction of corporate managers. Soc. Sci. J. 26, 75-92. doi: 10.1016/03623319(89)90039-6

Greenhaus, J. H., Parasuraman, S., and Wormley, W. M. (1990). Effects of race on organizational experiences, job-performance evaluations and career outcomes. Acad. Manage. J. 33, 64-86. doi: 10.2307/256352

Gushue, G. V., and Whitson, M. L. (2006). The relationship among support, ethnic identity, career decision self-efficacy, and outcome expectations in African American high school students: applying social cognitive career theory. J. Career Dev. 33, 112-124. doi: 10.1177/0894845306293416

Hackett, G., and Betz, N. E. (1981). A self-efficacy approach to the career development of women. J. Vocat. Behav. 18, 326-339. doi: 10.1016/00018791(81)90019-1

Hair, J. F., Anderson, R. E., Tatham, R. L., and Black, W. C. (1995). Multivariate Data Analysis, 4th Edn. River, NJ: Prentice-Hall, Inc.

Hall, D. T. (2002). Careers in and out of Organizations. Thousand Oaks, CA: Sage.

Hall, D. T., and Chandler, D. E. (2005). Psychological success: when the career is a calling. J. Organ. Behav. 26, 155-176. doi: 10.1002/job.301

Hassan, M., Akram, A., and Naz, S. (2012). The relationship between person organization fit, person-job-fit and turnover intention in banking sector of Pakistan: The mediating role of psychological climate. Int. J. Hum. Resour. Stud. 2, 172. doi: 10.5296/ijhrs.v2i3.2286

Heslin, P. A. (2005). Conceptualizing and evaluating career success. J. Organ. Behav.: The International Journal of Industrial, Occupational and Organizational Psychology and Behavior 26, 113-136. doi: 10.1002/job.270

Hoyle, R. H., and Sherrill, M. R. (2006). Future orientation in the self-system: possible selves, self-regulation, and behavior. J. Pers. 74, 1673-1696. doi: 10. 1111/j.1467-6494.2006.00424.x

Hu, L. T., and Bentler, P. M. (1999). Cutoff criteria for fit indexes in covariance structure analysis: conventional criteria versus new alternatives. Struct. Equat. Model. 6, 1-55. doi: 10.1080/10705519909540118

Huppert, F. A. (2009). Psychological well-being: evidence regarding its causes and consequences. Appl. Psychol. - Hlth. We 1, 137-164. doi: 10.1111/j.1758-0854. 2009.01008.x

Iverson, R. D., and Maguire, C. (2000). The relationship between job and life satisfaction: Evidence from a remote mining community. Hum. Relat. 53, 807-839. doi: 10.1177/0018726700536003

Jin, L., Watkins, D., and Yuen, M. (2009). Personality, career decision selfefficacy and commitment to the career choices process among Chinese graduate students. J. Vocat. Behav. 74, 47-52. doi: 10.1016/j.jvb.2008.10.002

Judge, T. A., and Bretz, R. D. Jr. (1994). Political influence behavior and career success. J. Manage. 20, 43-65. doi: 10.1177/014920639402000103

Judge, T. A., Klinger, R. L., and Simon, L. S. (2010). Time is on my side: time, general mental ability, human capital, and extrinsic career success. J. Appl. Psychol. 95, 92-107. doi: 10.1037/a0017594

Kahneman, D., Diener, E., and Schwarz, N. (eds) (1999). Well-being: Foundations of hedonic psychology. Russell: Sage Foundation. 
Kanfer, R., Wanberg, C. R., and Kantrowitz, T. (2001). Job search and employment: a personality-motivational analysis and meta-analytic review. J. Appl. Psychol. 86, 837-855. doi: 10.1037/0021-9010.86.5.837

Kihlstrom, J. F., and Cantor, N. (1984). "Mental representations of the self", in Advances in experimental social psychology, Vol. 17, ed. L. Berkowitz (New York: Academic Press), 1-47.

Kok, B. E., Coffey, K. A., Cohn, M. A., Catalino, L. I., Vacharkulksemsuk, T., Algoe, S. B., et al. (2013). How positive emotions build physical health: perceived positive social connections account for the upward spiral between positive emotions and vagal tone. Psychol. Sci 24, 1123-1132. doi: 10.1177/ 0956797612470827

Korsgaard, M. A., and Roberson, L. (1995). Procedural justice in performance evaluation-The role of instrumental and noninstrumental voice in performance-appraisal discussions. J. Manage 21, 657-669. doi: 10.1016/0149-2063(95)90004-7

Lee, Y. T., Reiche, B. S., and Song, D. (2010). How do newcomers fit in? The dynamics between person-environment fit and social capital across cultures. Int. J. Cross Cul. Manage. 10, 153-174. doi: 10.1177/1470595810370911

Lent, R. W., Brown, S. D., and Hackett, G. (1994). Toward a unifying social cognitive theory of career and academic interest, choice, and performance. J. Vocat. Behav. 45, 79-122. doi: 10.1006/jvbe.1994.1027

Lent, R. W., Brown, S. D., and Hackett, G. (2000). Contextual supports and barriers to career choice: a social cognitive analysis. J. Couns. Psychol. 47, 36-49. doi: 10.1037/0022-0167.47.1.36

Li, M., Wang, Z., Gao, J., and You, X. (2017). Proactive personality and job satisfaction: The mediating effects of self-efficacy and work engagement in teachers. Curr. Psychol. 36, 48-55. doi: 10.1007/s12144-015-9383-1

Lin, Y.-C., Yu, C., and Yic, C. (2014). The effects of positive affect, person-job fit, and well-being on job performance. Soc. Behav. Personal. 42, 1537-1548. doi: 10.2224/sbp.2014.42.9.1537

Liu, W., Li, Z., Ling, Y., and Cai, T. (2016). Core self-evaluations and coping styles as mediators between social support and well-being. Pers. Indiv. Differ. 88, 35-39. doi: 10.1016/j.paid.2015.08.044

Locke, E. A. (1967). Motivational effects of knowledge of results. J. Applied Psychol. 51, 324-329. doi: 10.1037/h0026737

Locke, E. A., Cartledge, N., and Koeppel, J. (1968). Motivational effects of knowledge of results: a goal-setting phenomenon? Psychol. Bull 70(6pt1), 474-485.

Locke, E. A., and Latham, G. P. (2006). New directions in goal-setting theory. Curr. Dir. Psychol. Sci. 15, 265-268. doi: 10.1111/j.1467-8721.2006.00449.x

Magee, W. (2013). Anxiety, demoralization, and the gender difference in job satisfaction. Sex Roles. 695, 308-322. doi: 10.1007/s11199-013-0297-9

Major, B. C., Le Nguyen, K. D., Lundberg, K. B., and Fredrickson, B. L. (2018). Well-being correlates of perceived positivity resonance: evidence from trait and episode-level assessments. Personal. Soc. Psychol. Bull. 44, 1631-1647. doi: $10.1177 / 0146167218771324$

Mayrhofer, W., Briscoe, J. P., Hall, D. T., Dickmann, M., Dries, N., and Dysvik, A. (2016). Career success across the globe: insights from the $5 \mathrm{c}$ project. Organ. Dyn. 45, 197-205. doi: 10.1016/j.orgdyn.2016.07.005

Ng, T. W. H., and Feldman, D. C. (2014). Subjective career success: a meta-analytic review. J. Vocat. Behav. 85, 169-179. doi: 10.1016/j.jvb.2014.06.001

Pan, J., Zhao, H., Zhou, W., and Gong, M. (2016). What I have gotten is not what I want - Multi-dimensional analysis on the influence of the differences between career success and the career success evaluation on happiness. Hum. Resou. Dev. China 11, 6-17. doi: 10.16471/j.cnki.11-2822/c.2016.11.001 (In Chinese),

Pan, J., and Zhou, W. (2015). How do employees construe their career success: An improved measure of subjective career success. Int. J. Select. Assess. 23, 45-58. doi: $10.1111 /$ ijsa.12094

Pan, J. Z., and Zhou, W. X. (2013). Can success lead to happiness? The moderators between career success and happiness. Asia Pac. J. Hum. Resou. 51, 63-80. doi: $10.1111 / j .1744-7941.2012 .00033 . x$

Peng, Y., and Mao, C. (2015). The impact of person-job fit on job satisfaction: The mediator role of self efficacy. Soc. Indic. Res. 121, 805-813. doi: 10.1007/s11205014-0659-x

Podsakoff, P. M., MacKenzie, S. B., Lee, J. Y., and Podsakoff, N. P. (2003). Common method biases in behavioral research: a critical review of the literature and recommended remedies. J. Appl. Psychol. 88, 879. doi: 10.1037/0021-9010.88. 5.879
Podsakoff, P. M., and Organ, D. W. (1986). Self-reports in organizational research: Problems and prospects. J. Manage. 12, 531-544. doi: 10.1177/ 014920638601200408

Preacher, K. J., and Hayes, A. F. (2008). Assessing Mediation in Communication Research. London: The Sage sourcebook of advanced data analysis methods for communication research, 13-54.

Ryan, R. M., and Deci, E. L. (2001). On happiness and human potentials: A review of research on hedonic and eudaimonic well-being. Annu. Rev. Psychol. 52, 141-166. doi: 10.1146/annurev.psych.52.1.141

Saks, A. M., and Ashforth, B. E. (1997). A longitudinal investigation of the relationships between job information sources, applicant perceptions of fit, and outwork comes. Pers. Psychol. 50, 395-426. doi: 10.1111/j.1744-6570.1997. tb00913.x

Savickas, M. L. (2013). Career construction theory and practice. Career Dev. Couns. Putting theory and research to work. 2, 147-183.

Seibert, S. E., Crant, J. M., and Kraimer, M. L. (1999). Proactive personality and career success. J. Appl. Psychol. 84, 416. doi: 10.1037/0021-9010.84.3.416

Sin, N. L., and Lyubomirsky, S. (2009). Enhancing well-being and alleviating depressive symptoms with positive psychology interventions: a practicefriendly meta-analysis. J. Clin. Psychol. 65, 467-487. doi: 10.1002/jclp.20593

Sortheix, F. M., Chow, A., and Salmanazar, K. (2015). Work values and the transition to work life: a longitudinal study. J. Vocat. Behav. 2015, 162-171. doi: $10.1016 /$ j.jvb.2015.06.001

Strauss, K., Griffin, M. A., and Parker, S. K. (2012). Future work selves: how salient hoped-for identities motivate proactive career behaviors. J. Applied Psychol. 97, 580-598. doi: 10.1037/a0026423

Stumpf, S. A. (2014). A longitudinal study of career success, embeddedness, and mobility of early career professionals. J. Vocat. Behav. 85, 180-190. doi: 10.1016/ j.jvb.2014.06.002

Taber, B. J., and Blankemeyer, M. (2015). Future work self and career adaptability in the prediction of proactive career behaviors. J. Vocat. Behav. 86, 20-27. doi: 10.1016/j.jvb.2014.10.005

Tinsley, H. E. A. (2000). The congruence myth: an analysis of the efficacy of the person-environment fit model. J. Vocat. Behav. 56, 147-179. doi: 10.1006/jvbe. 1999.1727

Visagie, S., and Koekemoer, E. (2014). What it means to succeed: personal perceptions of career success held by senior managers. S. Afr. J. Bus. Manag. 45, 43-54. doi: 10.4102/sajbm.v45i1.116

Wang, Q., Bowling, N. A., and Eschleman, K. J. (2010). A meta-analytic examination of work and general locus of control. J. Applied Psychol. 95, 761. doi: $10.1037 / \mathrm{a} 0017707$

Waterman, A. S. (1993). Two conceptions of happiness: contrasts of personal expressiveness (eudaimonia) and hedonic enjoyment. J. Pers. Soc. Psychol. 64, 678-691. doi: 10.1037/0022-3514.64.4.678

Watson, D., Clark, L. A., and Tellegen, A. (1988). Development and validation of brief measures of positive and negative affect: the PANAS scales. J. Pers. Soc. Psychol. 54, 1063.

Xin, L., Zhou, W., and Tang, F. (2019). Antecedents of career success criteria clarity: based on social cognitive career theory. Business Management Journal 4, 127-141. doi: 10.19616/j.cnki.bmj.2019.04.008

Zhou, W., Guan, Y., Xin, L., Mak, M. C. K., and Deng, Y. (2016). Career success criteria and locus of control as indicators of adaptive readiness in the career adaptation model. J. Vocat. Behav. 94, 124-130. doi: 10.1016/j.jvb.2016.02.015

Zhou, W., Sun, J., Guan, Y., Li, Y., and Pan, J. (2013). Criteria of career success among Chinese employees: developing a multi-dimensional scale with qualitative and quantitative approaches. J. Career Assess. 21, 265-277. doi: 10. $1177 / 1069072712471302$

Conflict of Interest: The authors declare that the research was conducted in the absence of any commercial or financial relationships that could be construed as a potential conflict of interest.

Copyright $\odot 2020 \mathrm{Xin}$, Zhou, Li and Tang. This is an open-access article distributed under the terms of the Creative Commons Attribution License (CC BY). The use, distribution or reproduction in other forums is permitted, provided the original author(s) and the copyright owner(s) are credited and that the original publication in this journal is cited, in accordance with accepted academic practice. No use, distribution or reproduction is permitted which does not comply with these terms. 